\title{
Twenty Five Years Ago: Still Looking at the Future
}

\author{
James R. Hemsley \\ VASARI Research Centre \& EVA Conference \\ Birkbeck, University of London \\ jrhemsley@hotmail.com
}

\section{INTRODUCTION}

The EVA London 1990 conference was not the first conference in the emerging field. To the best of our knowledge this honour belongs to the Computers and the History of Art (CHArt) conference which began in 1985 and also still continues. However, EVA London 1990 was the first such Europe-wide initiative with a focus on Museums and also for IT, Telecomms and Multi-media industries. The theme of the first week-long EVA London conference was 'Museum Applications in Europe' and was held at Imperial College. The programme was structured as follows:

- Monday July 23: The Visual Arts World Users' Needs. Speakers included from the French Ministry of Culture; The British Museum; The Doerner Institute (Bavarian State Painting Collections) and TUEVBavaria.

- Tuesday July 24: Input, Storage and Display Devices with speakers from BARCO, Crosfield Electronics; GEC Research, Thomson Video; Philips and Dupont Optical and the Technical University, Munich.

- Wednesday, July 25: Image Processing Software and Interactive Media, speakers including from Birkbeck; Thomson LER and Soft Option.

- Thursday, July 26: Case Studies and Exhibition, speakers including from The National Gallery; Birkbeck and the European DVI Developers Group.

- Friday, July 27: European Projects and Key Future Issues with the following projects represented: European Museum Network (EMN - Telecoms focus); EVAIN ('Observatory'); NARCISSE (Multimedia and Conservation) and VASARI (IT focus: Ultra High Quality Imaging and Education). Project partners included from Belgium, France, Germany, Italy, Netherlands, Spain and UK. Julio Cardoso of the EC also spoke.

A number of speakers tried to look towards 2000: with successes and failures!!

A central EVA Conference aim was to provide a forum for people from industry together with educationalists, museums and gallery staff to meet and exchange ideas' as well as for 'government, policy makers and others interested in shaping the European arts scene in the 1990s'. Pioneering computer artists had already been extremely active. Altogether over the week some 100 leading people in the still embryonic field participated including, for example, Professor Vito Cappellini, University of Florence and Director of the important Uffizi Project. The conference results confirmed the desire of the organisers to hold a second conference in 1991, the venue determined as UCL at the express invitation of Professor Derek Roberts, Provost of UCL who kindly chaired the second day, the other days by the two Conference Co-Chairs, Anthony Hamber, Birkbeck, University of London, and James R. Hemsley from Brameur which also provided the main administrative support led by Val Duncan as a key initiative of the VASARI project, An EVA Conference report was provided by Lindsay MacDonald (Advanced Imaging, September, 1990)

The VASARI project, with partial funding support from the EC's ESPRIT Programme. was inspired by the Musée d'Orsay and the Tate Gallery, as well as by Birkbeck, the National Gallery's Scientific Department and the Doerner Institute (Bavarian State Painting Collections) and CHArt. It was preceded by almost two years of Anglo-German planning and preparation. The full project consortium then included the Louvre and both large and small companies from France, Germany, Italy and the UK as well as a top Grande Ecole, ENST/Telecom Paris. The main thrust of the 
project was to develop a very high quality (resolution and colour) image capture system with positioning technology from the nuclear industry (Time and Precision Ltd.), a revolutionary digital camera from the Lenz brothers in Munich and advanced software from Birkbeck, the National Gallery and ENST. User goals of colour conservation, transportation damage measurement and education were the driving forces of VASARI, baptised by David Saunders (ex-National Gallery, now Head of the British Museum's Scientific Department): a homage to the Father of Art History, not just an EC project acronym (Visual Arts System for the Archiving and Retrieval of Images). An influential press account was published in the Financial Times (21 December, 1990); VASARI featured in Tomorrow's World (BBC)

In the Special Panel session former VASARI members consider questions such as:
- Memories, Impact and Legacy of the VASARI project. What didn't we dream of that happened in practice?

- How do you see now the next 5, 10, 15 years and beyond as regards Electronic Visualisation and the Arts?

Equal time is planned for looking backwards and looking forwards from July 2014. Panel members will include Professor Dr. Andreas Burmester, Director of the Doerner Institute, Munich; Dr John Cupitt (ex-National Gallery, now Imperial College); $\mathrm{Dr}$ Anthony Hamber (ex-Birkbeck); Dr Kirk Martinez (ex-Birkbeck, now Southampton University) and $\mathrm{Dr}$ David Saunders. Monsieur Dominique Gonthier, the VASARI EC project officer, and other ex-VASARI members will, we hope, also provide contributions. 